\title{
Mycobacterium tuberculosis Infection among Asian Elephants in Captivity
}

\author{
Gary Simpson, Ralph Zimmerman, \\ Elena Shashkina, Liang Chen, Michael Richard, \\ Carol M. Bradford, Gwen A. Dragoo, \\ Rhonda L. Saiers, Charles A. Peloquin, \\ Charles L. Daley, Paul Planet, Apurva Narechania, \\ Barun Mathema, Barry N. Kreiswirth
}

Although awareness of tuberculosis among captive elephants is increasing, antituberculosis therapy for these animals is not standardized. We describe Mycobacterium tuberculosis transmission between captive elephants based on whole genome analysis and report a successful combination treatment. Infection control protocols and careful monitoring of treatment of captive elephants with tuberculosis are warranted.

$\mathrm{O}$ ver the past 20 years, recognition of infection and disease caused by Mycobacterium tuberculosis in captive elephants and their keepers in the United States and globally has grown (1). We describe the diagnosis and treatment of 2 cases of active tuberculosis (TB), separated by 12 years, in 2 Asian elephants in a closed, captive population. In addition, we describe molecular and comparative genomic analysis of M. tuberculosis strains cultured from each elephant to investigate transmission.

\section{The Study}

In July 1997, the city of Albuquerque, New Mexico, USA, acquired 2 elephants that had been subject to poor conditions in a small traveling circus. Elephant A, a 31-year-old Asian elephant, and elephant B, an 8-yearold African elephant, were quarantined together in an isolated section of the Albuquerque Biopark modified

Author affiliations: Albuquerque Biopark, Albuquerque, New Mexico, USA (G. Simpson, R. Zimmerman, M. Richard,

C.M. Bradford, G.A. Dragoo, R.L. Saiers); Rutgers University Public Health Research Institute, Newark, New Jersey, USA (E. Shashkina, L. Chen, B.N. Kreiswirth); University of Florida College of Pharmacy, Gainesville, Florida, USA (C.A. Peloquin); National Jewish Health, Denver, Colorado, USA (C.L. Daley); Children's Hospital of Philadelphia, Philadelphia, Pennsylvania, USA (P. Planet); American Museum of Natural History Sackler Institute for Comparative Genomics, New York, New York, USA (A. Narechania); Columbia University Mailman School of Public Health, New York (B. Mathema)

DOI: http://dx.doi.org/10.3201/eid2303.160726 to hold elephants. Quarterly trunk washings (2) taken from both elephants over the course of 1 year of quarantine were negative for $M$. tuberculosis by culture. Both elephants were subsequently transferred to the zoo in late 1998.

Trunk washings taken from the zoo's elephant herd every 6 months were negative for M. tuberculosis by culture until October 2000, when a specimen from elephant A was found to be positive on 7H11 bi-plates. Elephant A had TB diagnosed and was isolated and monitored, having 3 trunk washings collected over each 7-day period; this cycle continued until week 12 of treatment, when all 3 washings from that week were negative for M. tuberculosis. Among the 13 cultured M. tuberculosis isolates recovered from 6 different collections, IS6110 genetic analysis $(3,4)$ identified 3 different strains (Figure 1). Antimycobacterial susceptibility testing (5) revealed that 1 strain was mono-rifampin resistant and all others were pansusceptible.

Initial treatment efforts included an anti-TB regimen of isoniazid $(5 \mathrm{mg} / \mathrm{kg})$, rifampin $(10 \mathrm{mg} / \mathrm{kg})$, and pyrazinamide $(25 \mathrm{mg} / \mathrm{kg})$. This regimen was initially given orally, but the administration failed because of elephant's A refusal to ingest the medication despite attempts to disguise or mix the drugs with treats or other food. As a result, isoniazid and pyrazinamide were given rectally, with serum concentrations obtained at 1,2 , and 4 hours after administration. This regimen was continued daily for 2 months, then every other day (QOD) for 1 year (Figure 2 ). The lengthy 3-month period until trunk washings were negative for $M$. tuberculosis by culture, the use of only 2 drugs, and the switch to a QOD regimen after only 2 months raised concern that elephant A's treatment was suboptimal. In particular, pyrazinamide attacks a specific subpopulation of organisms, and in humans, the selection of drug resistance to other agents in the treatment regimen is increased (6).

In response to elephant A's $M$. tuberculosis-positive trunk washings and contact history, elephant B was segregated from the herd and given isoniazid rectally QOD for 6 months as preventive therapy. Both elephants tolerated daily isoniazid poorly, having observable depression and loss of appetite. Clinical signs improved substantially with the start of QOD dosing, and both elephants completed therapy at the end of December 2001.

In December 2010, an Asian elephant (elephant C) had an M. tuberculosis-positive serologic test result by 
Chembio DPP VetTB Assay for Elephant (Chembio Diagnostic Systems, Inc., Medford, NY, USA) (7). An aggressive trunk washing testing cycle of 3 consecutive days on, followed by 3 days off, was initiated. A specimen from January 2011 produced a single colony of $M$. tuberculosis on 7H11 agar. Genetic analysis revealed an identical IS6110 fingerprint pattern (Figure 1, lane 6) to the predominant pansusceptible strains isolated from elephant A (Figure 1, lanes 2, 3, and 4). Elephant C's isolate was pansusceptible to all first-line anti-TB drugs. Treatment of elephant $\mathrm{C}$ was initiated in May 2011 by published guidelines (2); in this case, ethambutol was added to isoniazid and pyrazinamide with the same dosing used

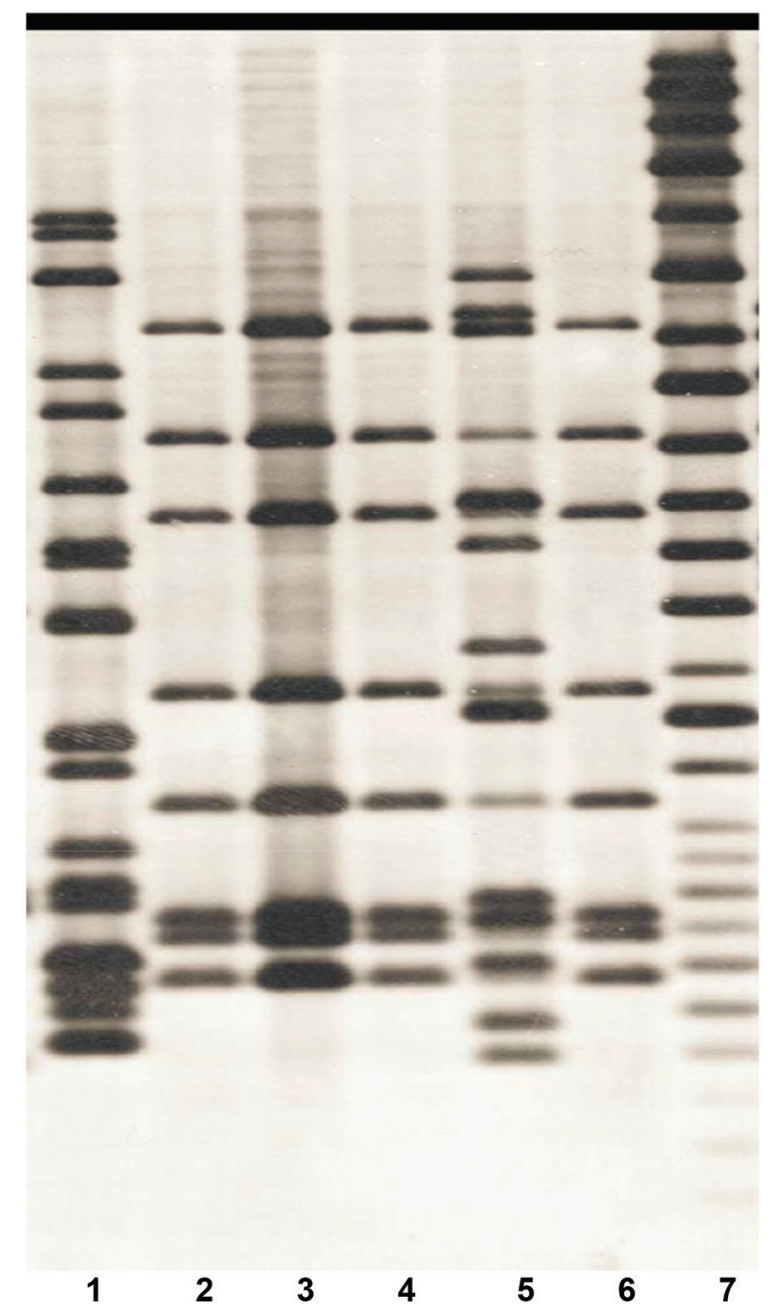

Figure 1. IS6110 Southern blot hybridization patterns of 6 Mycobacterium tuberculosis isolates recovered from elephants $A$ (lanes 1-5) and C (lane 6) (4) in study of tuberculosis in captive elephants, Albuquerque, New Mexico, USA, 1997-2013. The fingerprint pattern in lane 1 types the strain to principal genetic group 1, the fingerprint pattern in lanes $2-4$ and lane 6 types the strain to principal genetic group 2 and the fingerprint pattern in lane 5 types the strain to principal genetic group 3. Lane 7, molecular mass standard. to treat elephant A. Routine therapeutic monitoring of serum concentrations led to discontinuing ethambutol and instituting enrofloxacin, a 4-fluoroquinolone used primarily in veterinary settings (6). Treatment was completed after 18 months. The previous concern that elephant A had received suboptimal therapy led to her retreatment in concert with elephant $\mathrm{C}$.

A contact investigation was performed among the entire Albuquerque Biopark staff (178 persons) by using tuberculin skin testing and an interferon-gamma release assay $(8,9)$. No evidence of $M$. tuberculosis transmission was found.

The M. tuberculosis isolate recovered from elephant C exhibited an identical IS6110 fingerprint pattern to the EH3 isolate from elephant A (Figure 1). Although transmission between elephants $A$ and $C$ is not certain, exposure occurred before elephant's A first positive trunk washing, and no coincident TB disease was detected among the Albuquerque Biopark staff. More than 10 years after cohabitation with elephant $\mathrm{A}$ in the elephant barn, elephant $\mathrm{C}$ had onset of active TB caused by an isolate that had the identical IS6110 fingerprint to the infecting $M$. tuberculosis isolate from elephant A. Comparative whole genome sequencing analysis of the EH3 M. tuberculosis strains from elephants $\mathrm{A}$ and $\mathrm{C}$ was performed by using an Illumina MiSeq platform (Illumina, Inc., San Diego, CA, USA) (10). Single-nucleotide polymorphism (SNP) analysis revealed a total of $3 \mathrm{nt}$ changes (compared with the reference genome H37Rv [GenBank accession no. NC_000962]) at positions 10774 (C to T), 2492143 (C to $\bar{G}$ ), and 3013272 (T to $C$ ) during the 11-year period, a rate consistent with the modeled 0.3 SNPs per genome per year as previously reported $(10,11)$. The sequencing data has been deposited in the National Center for Biotechnology Information database under the BioProject ID no. PRJNA328788.

Recently, whole genome sequencing was used to analyze genetic variation among strains from relapsed patients with recurrent TB (10) and to establish genomic mutation rates in a study with nonhuman primates (11). Remarkably, both studies showed limited genomic variation and yielded the consensus that $M$. tuberculosis chromosomes change at a rate 0.3 SNPs per year.

\section{Conclusions}

Our whole-genome sequencing analysis confirmed the molecular identity of $2 \mathrm{M}$. tuberculosis isolates recovered 12 years apart from 2 captive elephants. The remarkable conservation between the 2 genomes is consistent with previous studies $(10,11)$. Because elephant $\mathrm{C}$ had routine trunk washings that were negative during this period and no intermittent shedding occurred, we believe elephant $C$ had latent TB and that elephant A was the source of the infection 


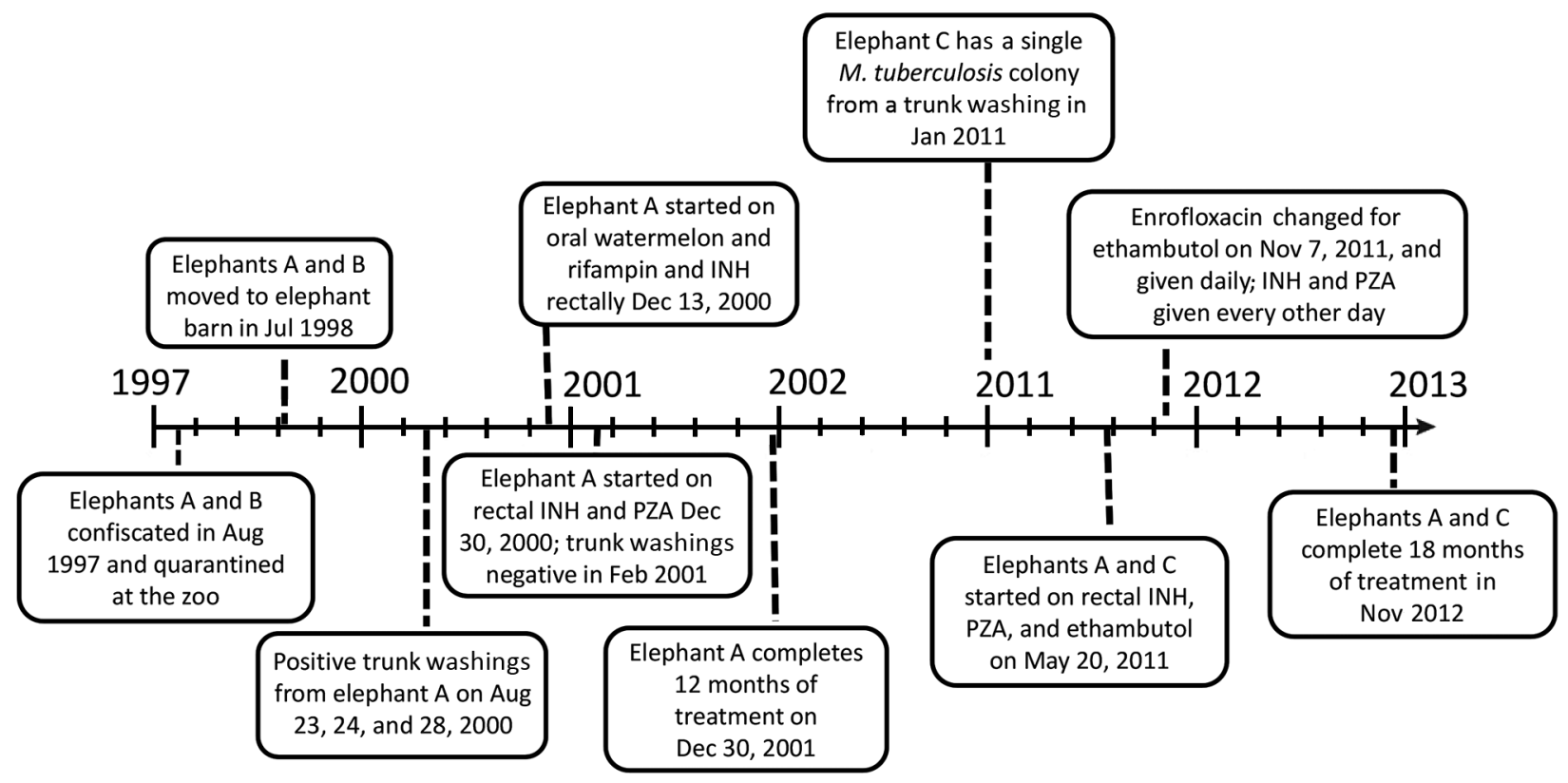

Figure 2. Annotated timeline documenting the course of events in study of tuberculosis in captive elephants, Albuquerque, New Mexico, USA, 1997-2013. INH, isoniazid; PZA pyrazinamide.

during their cohabitation. In support of the probable transmission between elephants $\mathrm{A}$ and $\mathrm{C}$, the records at the Albuquerque Biopark confirm that both elephants were barned at the end of the each day from July 1998 through August 2000, when elephant A had a positive trunk washing and was isolated.

Numerous challenges were met in managing the treatment and control of TB among the elephants in the Biopark, including the choice of antimycobacterial agents, their comprehensive delivery, and the appropriate length of treatment. Rectal administration proved the most efficacious, and this approach was adopted for treating elephants $\mathrm{A}$ and $\mathrm{C}$ and for preventive treatment of elephant B. The availability of enrofloxacin, a fluoroquinolone not used in human health, appeared to be an effective third agent to combine with isoniazid and pyrazinamide, although prospective study data are lacking. This $\$ 20,000$ regimen (per elephant per year) was ultimately used for 1 year to successfully treat elephant $\mathrm{C}$ and to retreat elephant $\mathrm{A}$. The fact that no skin test conversions or TB disease were documented among Biopark staff with epidemiologic association to the elephants supports the evidence that transmission did not involve humans at that location.

Dr. Simpson is an infectious disease physician with experience treating tuberculosis in humans. He is affiliated with the University of New Mexico, Texas Tech University, and the Albuquerque Biopark in Albuquerque, New Mexico, where he was involved in the care of elephants with tuberculosis.

\section{References}

1. Mikota SK, Peddie L, Peddie J, Isaza R, Dunker F, West G, et al. Epidemiology and diagnosis of Mycobacterium tuberculosis in captive Asian elephants (Elephas maximus). J Zoo Wildl Med. 2001;32:1-16. https://dx.doi.org/10.1638/1042-7260 (2001)032[0001:EADOMT]2.0.CO;2

2. Animal and Plant Health Inspection Service. Guidelines for the control of tuberculosis in elephants [cited 2012 April 20]. http://www.usaha.org/Portals/6/Committees/tuberculosis/TB\%20 Guidelines\%202012\%20Draft\%20revision\%2020April2012.pdf

3. Bifani P, Mathema B, Campo M, Moghazeh S, Nivin B, Shashkina E, et al. Molecular identification of streptomycin monoresistant Mycobacterium tuberculosis related to multidrug-resistant W strain. Emerg Infect Dis. 2001;7:842-8. http://dx.doi.org/10.3201/eid0705.010512

4. Gutacker MM, Smoot JC, Migliaccio CA, Ricklefs SM, Hua S, Cousins DV, et al. Genome-wide analysis of synonymous single nucleotide polymorphisms in Mycobacterium tuberculosis complex organisms: resolution of genetic relationships among closely related microbial strains. Genetics. 2002;162:1533-43.

5. Bemer P, Palicova F, Rüsch-Gerdes S, Drugeon HB, Pfyffer GE. Multicenter evaluation of fully automated BACTEC Mycobacteria Growth Indicator Tube 960 system for susceptibility testing of Mycobacterium tuberculosis. J Clin Microbiol. 2002;40:150-4. http://dx.doi.org/10.1128/JCM.40.1.150-154.2002

6. Zhu M, Maslow JN, Mikota SK, Isaza R, Dunker F, Riddle H, et al. Population pharmacokinetics of pyrazinamide in elephants. J Vet Pharmacol Ther. 2005;28:403-9. http://dx.doi.org/10.1111/ j.1365-2885.2005.00670.x

7. Lyashchenko KP, Greenwald R, Esfandiari J, Olsen JH, Ball R, Dumonceaux G, et al. Tuberculosis in elephants: antibody responses to defined antigens of Mycobacterium tuberculosis, potential for early diagnosis, and monitoring of treatment. Clin Vaccine Immunol. 2006;13:722-32. http://dx.doi.org/10.1128/ CVI.00133-06 
8. Michalak K, Austin C, Diesel S, Bacon MJ, Zimmerman P, Maslow JN. Mycobacterium tuberculosis infection as a zoonotic disease: transmission between humans and elephants. Emerg Infect Dis. 1998;4:283-7. http://dx.doi.org/10.3201/eid0402.980217

9. National Tuberculosis Controllers Association; Centers for Disease Control and Prevention (CDC). Guidelines for the investigation of contacts of persons with infectious tuberculosis. Recommendations from the National Tuberculosis Controllers Association and CDC. MMWR Recomm Rep. 2005;54(RR-15):1-47.

10. Bryant JM, Harris SR, Parkhill J, Dawson R, Diacon AH, van Helden P, et al. Whole-genome sequencing to establish relapse or re-infection with Mycobacterium tuberculosis: a retrospective observational study. Lancet Respir Med. 2013;1:786-92. http://dx.doi.org/10.1016/S2213-2600(13)70231-5

11. Ford CB, Lin PL, Chase MR, Shah RR, Iartchouk O, Galagan J, et al. Use of whole genome sequencing to estimate the mutation rate of Mycobacterium tuberculosis during latent infection. Nat Genet. 2011;43:482-6. http://dx.doi.org/10.1038/ng.811

Address for correspondence: Barry N. Kreiswirth, Public Health Research Institute TB Center, International Center for Public Health Building, 225 Warren St, Newark, NJ 07103, USA; email: kreiswba@njms.rutgers.edu

\begin{tabular}{|c|c|c|c|}
\hline $\begin{array}{l}\text { - Turtle-Associated } \\
\text { Salmonellosis, United } \\
\text { States, 2006-2014 } \\
\text { - Pregnancy, Labor, and } \\
\text { Delivery after Ebola Virus } \\
\text { Disease and Implications } \\
\text { for Infection Control } \\
\text { in Obstetric Services, } \\
\text { United States, 2015 } \\
\text { - Response to Middle East } \\
\text { Respiratory Syndrome } \\
\text { Coronavirus, Abu Dhabi, } \\
\text { United Arab Emirates, } \\
2013-2014 \\
\text { - Current Guidelines, } \\
\text { Common Clinical Pitfalls, } \\
\text { and Future Directions for } \\
\text { Laboratory Diagnosis of } \\
\text { Lyme Disease, United } \\
\text { - Tropheryma whipplei } \\
\text { as a Cause of Epidemic } \\
\text { Fever, Senegal, } \\
2010-2012\end{array}$ & $\begin{array}{l}\text { - Two Linked Enteroinvasive } \\
\text { Escherichia coli } \\
\text { Outbreaks, Nottingham, } \\
\text { United Kingdom, } \\
\text { June } 2014 \\
\text { - Porcine Bocavirus } \\
\text { Infection Associated with } \\
\text { Encephalomyelitis in a } \\
\text { Pig, Germany } \\
\text { - African Swine Fever } \\
\text { Epidemic, Poland, } \\
\text { 2014-2015 } \\
\text { - Hepatitis E Virus in } \\
\text { Dromedaries, North and } \\
\text { East Africa, United Arab } \\
\text { Emirates and Pakistan, } \\
\text { 1983-2015 } \\
\text { - Heatwave-Associated } \\
\text { Vibriosis, Sweden and } \\
\text { Finland, } 2014 \\
\text { - Vesicular Disease } \\
\text { in 9-Week-Old Pigs } \\
\text { Experimentally Infected } \\
\text { with Senecavirus A }\end{array}$ & $\begin{array}{l}\text { - High Incidence of } \\
\text { Chikungunya Virus and } \\
\text { Frequency of Viremic } \\
\text { Blood Donations during } \\
\text { Epidemic, Puerto Rico, } \\
\text { USA, } 2014 \\
\text { - Outbreak of Vibrio } \\
\text { parahaemolyticus } \\
\text { Sequence Type 120, } \\
\text { Peru, } 2009 \\
\text { - Clinical Manifestations } \\
\text { of Senecavirus A } \\
\text { Infection in Neonatal } \\
\text { Pigs, Brazil, } 2015\end{array}$ & $\begin{array}{l}\text { - Surveillance for Highly } \\
\text { Pathogenic Avian } \\
\text { Influenza Virus in Wild } \\
\text { Birds during Outbreaks } \\
\text { in Domestic Poultry, } \\
\text { Minnesota, } 2015 \\
\text { - Highly Pathogenic Avian } \\
\text { Influenza Viruses and } \\
\text { Generation of Novel } \\
\text { Reassortants, United } \\
\text { States, 2014-2015 } \\
\text { - Naturally Circulating } \\
\text { Hepatitis A Virus in Olive } \\
\text { Baboons, Uganda } \\
\text { - Detection and Genomic } \\
\text { Characterization of } \\
\text { Senecavirus A, } \\
\text { Ohio, USA, 2015 } \\
\text { - Red Fox as a Sentinel for } \\
\text { Blastomyces dermatitidis, } \\
\text { Ontario, Canada } \\
\text { - Senecavirus A in Pigs, } \\
\text { United States, } 2015\end{array}$ \\
\hline $\begin{array}{l}\text { EMERGING } \\
\text { INFECTIOUS DISEASES }\end{array}$ & & & \\
\hline
\end{tabular}

